\title{
Product Carbon Footprint of a Fabric Manufactured in Sri Lanka
}

\author{
Wahala W.M.P.S.B. ${ }^{*}$, Siriwardana H. ${ }^{1}$ and Senadheera D.K.L. ${ }^{2}$ \\ ${ }^{1}$ Department of Tourism Management, Sabaragamuwa University of Sri Lanka \\ ${ }^{2}$ Carbon Consulting Company, Sri Lanka \\ *sampathwahala@yahoo.co.uk
}

\begin{abstract}
Quantification of total greenhouse gas emission of a product throughout its life cycle is known as Product Carbon Footprint (PCF). Assessment of PCF of a product system measures the climate change impact of a product either from cradle- to- gate (raw material extraction to factory gate) or from cradle-to-grave (raw material extraction to final disposal of the product) methodology. The product footprint was conducted in one of the leading fabric manufacturing plant in Sri Lanka. In this study, PCF was applied to measure the climate change impact of three different products from the knit fabric production process within the boundary level of cradle-to-gate. The selected product was a cotton fabric and three main products were considered which have different compositions of materials. Each product has different production process routes and the main process stages involved in fabric manufacturing process are; knitting, dyeing and finishing process. The functional unit of the study was $1 \mathrm{~m}^{2}$ of fabric. All the material inflows and outflows to the product systems were considered when preparing the Life Cycle Inventory (LCI) of the three knitted fabric products separately. The main activity data considered are indirect emissions from transportation of raw materials, purchase electricity and direct emissions from generators, boilers and other process related emissions. The climate change impacts of these selected knitted fabric products were assessed in accordance with PAS 2050 and ISO standards. Umberto for carbon footprint version 1.2 software which is a flexible modeling was used to create a multi-phase product life cycle model and calculate the carbon footprint. The analysis results shown that, product 3 has the highest impacting on climate change and its amount is $3.2733 \mathrm{~kg} \mathrm{CO}_{2 \mathrm{e}}$ on average and product 1 and 2 showed a carbon footprint of $3.1606 \mathrm{~kg} \mathrm{CO}_{2 \mathrm{e}}$ on average and $3.0581 \mathrm{~kg} \mathrm{CO}_{2 \mathrm{e}}$ on average respectively. According to this study, raw material extraction and material processing phase has the highest impact on climate change as the embedded carbon of raw material has an high impact. and the second highest impact is from knitting and greige preparation phase.
\end{abstract}

Keywords: Knitted fabric, Product Carbon Footprint (PCF), Life Cycle Inventory (LCI), PAS 2050, Umberto for carbon footprint v 1.2

Proceedings of the International Forestry and Environment Symposium 2016, Department of Forestry and Environmental Science, University of Sri Jayewardenepura, Sri Lanka. 